\title{
Propofol induces apoptosis and ameliorates 5-fluorouracil resistance in OSCC cells by reducing the expression and secretion of amphiregulin
}

\author{
KUNG-SSU YANG ${ }^{1,2^{*}}$, PI-CHENG CHE ${ }^{1 *}$, MING-JU HSIEH ${ }^{3-5}$, I-NENG LEE $^{6}$, \\ YU-PING WU ${ }^{2,6}$, MING-SHAN CHEN ${ }^{1,2,7}$ and JUI-CHIEH CHEN $^{2}$ \\ ${ }^{1}$ Department of Anesthesiology, Ditmanson Medical Foundation Chia-Yi Christian Hospital, Chiayi 60002; \\ ${ }^{2}$ Department of Biochemical Science and Technology, National Chiayi University, Chiayi 60004; \\ ${ }^{3}$ Cancer Research Center, Changhua Christian Hospital, Changhua 500209; ${ }^{4}$ School of Optometry, \\ Chung Shan Medical University, Taichung $40201 ;{ }^{5}$ Graduate Institute of Biomedical Sciences, \\ China Medical University, Taichung 406040; ${ }^{6}$ Department of Medical Research, \\ Chang Gung Memorial Hospital, Chiayi 61363; ${ }^{7}$ Department of Medical Laboratory \\ Science and Biotechnology, Asia University, Taichung 41354, Taiwan, R.O.C.
}

Received August 5, 2021; Accepted September 29, 2021

DOI: $10.3892 / \mathrm{mmr} .2021 .12552$

\begin{abstract}
Among the different types of oral cancer, $>90 \%$ of cases are oral squamous cell carcinoma (OSCC). 5-fluorouracil (5-FU) is a commonly used treatment for OSCC, but cells typically display resistance to the drug. Propofol, an intravenous anesthetic agent, exhibits certain anticancer effects, including the inhibition of cancer cell proliferation, migration and invasion. Secreted proteins, such as growth factors and cytokines are involved in cancer development and progression, but the effect of propofol on secreted proteins in OSCC is not completely understood. An MTT assay, flow cytometry and western blotting were performed to determine the anticancer effects of propofol. The secretion profile of OSCC was determined using an antibody array, and clinical importance was assessed using the Gene Expression Profiling Interactive Analysis database. The results were verified by performing reverse transcription-quantitative
\end{abstract}

Correspondence to: Professor Jui-Chieh Chen, Department of Biochemical Science and Technology, National Chiayi University, Multi-Purpose Instruction Building, 300 Syuefu Road, Chiayi 60004, Taiwan, R.O.C.

E-mail: jcc@mail.ncyu.edu.tw

Dr Ming-Shan Chen, Department of Anesthesiology, Ditmanson Medical Foundation Chia-Yi Christian Hospital, 539 Jhongsiao Road, Chiayi 60002, Taiwan, R.O.C.

E-mail:06590@cych.org.tw

*Contributed equally

Key words: oral squamous cell carcinoma, propofol, amphiregulin, 5-fluorouracil, drug resistance, secreted protein
PCR (RT-qPCR) and western blotting. 5-FU-resistant cells were established to determine the role of the gene of interest in drug resistance. The results demonstrated that propofol decreased cell viability and promoted cell apoptosis. The antibody array results showed that propofol attenuated the secretion of multiple growth factors. The bioinformatics results indicated that amphiregulin (AREG) was expressed at significantly higher levels in cancer tissues, which was also related to poor prognosis. The results of RT-qPCR and western blotting revealed that propofol decreased AREG expression. Pretreatment with exogenous recombinant AREG increased EGFR activation and conferred propofol resistance. Moreover, the results indicated that the expression and activation of AREG was also related to 5-FU resistance, but propofol ameliorated 5-FU drug resistance. Therefore, the present study suggested that propofol combination therapy may serve as an effective treatment strategy for OSCC.

\section{Introduction}

Oral squamous cell carcinoma (OSCC) is the most common subset of head and neck squamous cell carcinoma (HNSCC) (1). Clinical treatment of OSCC includes surgery, radiotherapy and chemotherapy (2). Multiple treatment strategies have improved the clinical outcome for patients with OSCC, but the overall 5-year survival rate after diagnosis is still $<50 \%$ (3). As with other solid tumors, 5-fluorouracil (5-FU) is one of the most effective and commonly used drugs for OSCC (4), but its clinical effectiveness is often limited due to acquired resistance with continuous drug administration (5). Therefore, identifying an effective therapeutic drug to improve the prognosis of patients with OSCC is important.

Propofol (2, 6-diisopropylphenol) is a commonly used intravenous sedative-hypnotic drug that allows for smooth 
induction and a rapid recovery from anesthesia (6). Propofol also displays a number of non-anesthetic effects, including antitumor activities $(7,8)$. In a variety of human cancer cells, it has been reported that propofol triggers cell apoptosis and inhibits proliferation, migration and invasion $(9,10)$. Certain retrospective studies and prospective trials have reported that propofol treatment improves the survival outcomes for patients with certain types of cancer after tumor resection (11-16). However, the role of propofol in the treatment of OSCC is not completely understood.

Secreted substances are responsible for communication between cells and may promote tumor progression (17). Increasing evidence demonstrates that the microenvironment is the primary driver for cancer growth, motility and therapy resistance (18-20). Secretions from cells can also enter the blood system and serve as serum tumor markers. A recent study showed that for patients undergoing radical resection for non-small cell lung cancer (NSCLC), propofol reduced postoperative serum tumor angiogenesis-related factors, such as VEGF and TGF- $\beta$ (21), thus propofol may affect the tumor microenvironment and serve a pivotal role in the development and progression of cancer.

Antibody arrays are extensively utilized in cancer research to identify candidate biomarkers and explore signaling pathways, which benefits diagnosis, prognosis and treatment (22). Numerous biological websites and software can be used for bioinformatics analysis, including gene expression profile interactive analysis (GEPIA) (23), which has been successfully applied in numerous cancer studies. The present study investigated the effect of propofol on OSCC cytotoxicity and the secreted protein profile using an antibody array. Bioinformatics tools are used to evaluate the clinical importance of these altered secreted proteins.

\section{Materials and methods}

Chemicals and reagents. Propofol (purity $>98 \%$ ) was obtained from The United States Pharmacopeial Convention. 5-FU was purchased from Sigma-Aldrich (Merck KGaA). Propofol and 5-FU were dissolved in DMSO (Amresco, LLC) and stored at $4^{\circ} \mathrm{C}$ before use. Recombinant AREG (rAREG) was purchased from R\&D Systems, Inc.

Cell culture. Human OSCC cell lines (SAS and SCC9) were cultured in DMEM (Gibco; Thermo Fisher Scientific, Inc.) containing 10\% FBS (Gibco; Thermo Fisher Scientific, Inc.) and $1 \%$ penicillin-streptomycin, and maintained at $37^{\circ} \mathrm{C}$ in a humidified atmosphere of $5 \% \mathrm{CO}_{2}$.

Cell cytotoxicity. The cytotoxic activity of propofol on OSCC cells was assessed using an MTT assay. Cells $\left(5 \times 10^{3} /\right.$ well) in $100 \mu \mathrm{l}$ medium were plated in each well of a 96-well plate overnight. Subsequently, cells were treated with the indicated concentrations of propofol $(0,5,10,20$, $40,80$ and $160 \mu \mathrm{M})$ or $5-\mathrm{FU}(0-160 \mu \mathrm{M})$ for the indicated interval $(24,48$ or $72 \mathrm{~h})$. Then, MTT reagent $(5 \mathrm{mg} / \mathrm{ml}$ in PBS) was added to each well and incubated for $4 \mathrm{~h}$. The supernatant was removed and $100 \mu \mathrm{l}$ DMSO was added to each well to dissolve the formazan crystals. The absorbance was measured at a wavelength of $550 \mathrm{~nm}$ using a microplate reader, and the background value at a wavelength of $750 \mathrm{~nm}$ was subtracted. Cell viability is presented as the percentage relative to untreated cells.

Detection of the apoptotic rate by flow cytometry. Cells $\left(1.5 \times 10^{5}\right.$ cells/well) were seeded into 6 well plates and cultured overnight. After treatment with $160 \mu \mathrm{M}$ propofol for $48 \mathrm{~h}$ at $37^{\circ} \mathrm{C}$, cells were collected and washed with cold PBS. The Annexin V FITC/PI Apoptosis Detection kit (BD Biosciences) was used to detect cell apoptosis. After staining at $25^{\circ} \mathrm{C}$ in the dark for $15 \mathrm{~min}$, the apoptotic rate was determined by BD FACSCanto ${ }^{\mathrm{TM}}$ II flow cytometer (BD Biosciences). Data acquisition was performed using FACSDiva software version 6.1 (BD Biosciences). The apoptotic rate (\%) was calculated as the sum of Annexin-V-FITC ${ }^{+} / \mathrm{PI}^{-}$(early apoptosis; Q4) and Annexin-V-FITC ${ }^{+} / \mathrm{PI}^{+}$(late apoptosis; Q4) cells.

Western blotting. Total protein was isolated from cells using RIPA buffer supplemented with a protease inhibitor cocktail. A Pierce BCA Protein Assay Kit (Thermo Fisher Scientific, Inc.) was used to determine protein concentrations. Equal amounts of total protein $(40 \mu \mathrm{g} /$ lane $)$ were separated by SDS-PAGE (8-15\% gel) and then transferred to PVDF membranes (Millipore). After blocking with 5\% skimmed milk in TBS at room temperature for $1 \mathrm{~h}$, the membranes were incubated with specific primary antibodies overnight at $4^{\circ} \mathrm{C}$. The following primary antibodies were used: Cleaved PARP $(1: 2,000$; cat. no. ab32064; Abcam), $\alpha$-tubulin (1:10,000; cat. no. 05-829; EMD Millipore), AREG (1:200; cat. no. sc-74501; Santa Cruz Biotechnology, Inc.), phosphorylated (p)-EGFR (1:1,000; cat. no. 6963S; Cell Signaling Technology, Inc.), and EGFR (1: 200; cat. no. sc-53274; Santa Cruz Biotechnology, Inc.). After several washes with TBST $(0.05 \%$ Tween-20), the membranes were then incubated for $1 \mathrm{~h}$ with appropriate HRP-conjugated goat anti-rabbit IgG (1:5,000; cat. no. 20202; Leadgene Biomedical, Inc.) and goat anti-mouse IgG (1:5,000; cat. no. 115-035-003; Jackson ImmunoResearch Laboratories, Inc.) secondary antibodies. The membranes were then washed with TBST and protein bands were visualized using ECL reagents (Merck KGaA) and autoradiography. The intensity of signals was recorded using UN-SCAN-IT gel 6.1 software (Silk Scientific, Inc.).

Preparation of conditioned media (CM). Cells were cultured in DMEM until they reached $70 \%$ confluence. The adherent cells were washed three times with PBS to remove FBS, and then cultured in serum-free DMEM for $48 \mathrm{~h}$. The culture media was collected, centrifuged at $500 \mathrm{x} g$ at room temperature for $15 \mathrm{~min}$ and then carefully aspirated to collect the CM. Amicon ${ }^{\circledR}$ Ultra (Merck KGaA) with a $3 \mathrm{kDa}$ cut-off value was used to increase the protein concentration by centrifugation at $2,000 \mathrm{x} \mathrm{g}$ at $4^{\circ} \mathrm{C}$ for $3 \mathrm{~h}$. The resultant $\mathrm{CM}$ was stored at $-80^{\circ} \mathrm{C}$ until further use. An equal amount of conditioned culture media $(40 \mu \mathrm{g})$ was analyzed by $15 \%$ SDS-PAGE and transferred to PVDF membrane, after which the membrane was stained with Ponceau $\mathrm{S}$ at room temperature for $5 \mathrm{~min}$ as a loading control.

Human growth factor antibody array. An Human Growth Factor Antibody Array Membrane (41 Targets; 
cat. no. ab134002; Abcam) containing 41 targets was used to determine changes in secreted proteins after propofol treatment. The membrane was blocked by incubating at room temperature for $30 \mathrm{~min}$ with $1 \mathrm{X}$ blocking buffer (provided in the kit). The array membrane was incubated with $200 \mu \mathrm{g}$ concentrated $\mathrm{CM}$ sample overnight at $4^{\circ} \mathrm{C}$. After washing (reagent provided in the kit), the membrane was incubated with the primary antibody cocktail for overnight at $4^{\circ} \mathrm{C}$, washed and then incubated with the secondary antibody for $2 \mathrm{~h}$ at room temperature. Subsequently, bound antibodies were visualized using ECL reagents. The primary antibody cocktail, secondary antibody and ECL reagents were all provided as part of the array kit. The relative intensity of the signal was calculated using UN-SCAN-IT gel 6.1 software (Silk Scientific, Inc.). The background (negative control) was subtracted from the intensity of the dot signal and normalized using the average value for the positive control spots.

GEPIA analysis. GEPIA is an online web server that uses The Cancer Genome Atlas (TCGA) and Genotype-Tissue Expression (GTEx) data. The TCGA included the RNA-Seq data of 9,736 tumor samples with 33 cancer types and 726 adjacent normal tissues. GTEx included the RNA-Seq data of $>8,000$ normal samples. The datasets were both stored in a MySQL relational database (version 5.7.17) (23). The present study used GEPIA to determine the clinical importance of the candidate genes identified by the antibody array. The gene name was set as 'AREG' and 'HNSCC' datasets were used for the analysis. The expression data were the first $\log 2(\mathrm{TPM}+1)$ transformed data that were used for differential analysis. The $\log 2 \mathrm{FC}$ was defined as median (tumor) - median (normal). The $\mathrm{ILog} 2 \mathrm{FCl}$ cutoff was 1 . The cutoff value for $\mathrm{P}$ was 0.05 . Log2 $(\mathrm{TPM}+1)$ where TPM = Transcripts Per Million was used for the log-scale. Whisker plots show the relative RNA expression for candidate genes between HNSCC tissues $(n=519)$ and normal tissues $(n=44)$. GEPIA was also used to determine the relationship between the expression level for candidate genes and overall survival (OS) for patients with HNSCC.

Reverse transcription-quantitative PCR ( $q P C R)$. Total RNA was extracted from cells using TRIzol ${ }^{\circledR}$ reagent (Thermo Fisher Scientific, Inc.). RNA was reverse transcribed into cDNA using the PrimeScript RT Reagent kit (Takara Bio, Inc.) according to the manufacturer's protocol. Subsequently, qPCR was performed using Kapa SYB ${ }^{\circledR}$ FAST qPCR Master Mix (Takara Bio, Inc.) and the MyGo PCR detection system (IT-IS Life Science Ltd.). The thermocycling conditions were as follows: Initial denaturation at $95^{\circ} \mathrm{C}$ for $180 \mathrm{sec}$, followed by 40 cycles at $95^{\circ} \mathrm{C}$ for $10 \mathrm{sec}, 60^{\circ} \mathrm{C}$ for $20 \mathrm{sec}$ and $72^{\circ} \mathrm{C}$ for $30 \mathrm{sec}$. The following primers were used for qPCR: AREG forward, 5'-ACCTACTCTGGGAAGCGTGA-3' and reverse, 5'-GGACTTTTCCCCACACCGTT-3'; and GAPDH forward, 5'-CACCCATGGCAAATTCCATGGCA-3' and reverse, 5'-TCTAGACGGCAGGTCAGGTCCACC-3'. AREG mRNA expression was quantified using the $2^{-\triangle \Delta C q}$ method and normalized to the internal reference gene GAPDH (24).

Human EGFR phosphorylation antibody array. Cells were pre-starved in serum-free DMEM for $4 \mathrm{~h}$, and then stimulated for 15 min with serum-free DMEM containing human $\mathrm{rAREG}$ protein (50 $\mathrm{ng} / \mathrm{ml}$; R\&D Systems, Inc.) at $37^{\circ} \mathrm{C}$. A Human EGFR Phosphorylation Antibody Array-Membrane (17 Targets; cat. no. ab134005; Abcam) was used to determine changes in EGFR activation after rAREG treatment. The membrane was blocked by incubating at room temperature for $1 \mathrm{~h}$ with $1 \mathrm{X}$ blocking buffer (provided in the kit). The array membrane was then incubated with cell lysates $(200 \mu \mathrm{g} / \mathrm{ml})$ overnight at $4^{\circ} \mathrm{C}$. After washing (reagent provided in the kit), the membrane was incubated with a biotin-conjugated anti-EGFR cocktail (reagent provided in the kit) overnight at $4^{\circ} \mathrm{C}$, washed (reagent provided in the kit) and subsequently incubated with the HRP-conjugated streptavidin for $2 \mathrm{~h}$ at room temperature. The signals are visualized using ECL reagents (provided in the kit) and autoradiography. In addition, SAS and SCC9 cells were treated with rAREG (50-100 $\mathrm{ng} / \mathrm{ml})$ and analyzed by western blot to verify the activation of EGFR.

Establishment of 5-FU-resistant (FUR) sublines. To determine the mechanism underlying 5-FU resistance, SCC9 cells were cultured in the completed medium with gradually increasing concentrations of 5-FU from 0.5 to $160 \mu \mathrm{M}$. After $\sim 6$ months, cells survived in three different concentrations of 5-FU (40, 80 and $160 \mu \mathrm{M})$. Cells with different levels of 5-FU-resistance were named SCC9-FUR40, SCC9-FUR80 and SCC9-FUR160 cells, respectively.

AREG overexpression. SCC9 cells were seeded at a density of $3 \times 10^{5}$ cells $/ 6 \mathrm{~cm}$ culture dish, after which cells were cultured in completed medium overnight at $37^{\circ} \mathrm{C}$ with $5 \% \mathrm{CO}_{2}$. SCC9 cells were transfected with AREG overexpression plasmid (1 $\mu \mathrm{g}$; pCMV3-AREG) or empty vector (1 $\mu \mathrm{g}$; pCMV3) using TurboFect transfection reagent (Thermo Fisher Scientific, Inc.). Following overnight incubation at $37^{\circ} \mathrm{C}$, the medium was replaced with fresh complete medium, and the cells received a second incubation of $24 \mathrm{~h}$ at $37^{\circ} \mathrm{C}$. All plasmids were purchased from Sino Biological Inc. The amino acid sequence of AREG overexpression was as follows: MRAPLLPPAPVVLSLLILGSGHYAAGLDLNDTYSGKR EPFSGDHSADGFEVTSRSEMSSGSEISPVSEMPSSSEPSS GADYDYSEEYDNEPQIPGYIVDDSVRVEQVVKPPQNK TESENTSDKPKRKKKGGKNGKNRRNRKKKNPCNAEF QNFCIHGECKYIEHLEAVTCKCQQEYFGERCGEKSMKT HSMIDSSLSKIALAAIAAFMSAVILTAVAVITVQLRRQYV RKYEGEAEERKKLRQENGNVHAIA. After transfection, cells were cultured for $48 \mathrm{~h}$ and then harvested to determine the transfection efficiency via western blotting. The effect of AREG overexpression on 5-FU sensitivity was also determined using a MTT assay.

Statistical analysis. Data are presented as the mean \pm SEM of at least three independent experiments. Statistical analyses were performed using GraphPad Prism software (version 6.0; GraphPad Software, Inc.). Comparisons between two groups were analyzed using the unpaired Student's t-test. Comparisons among multiple groups were analyzed using one-way ANOVA followed by Bonferroni's post hoc test. $\mathrm{P}<0.05$ was considered to indicate a statistically significant difference. 
A

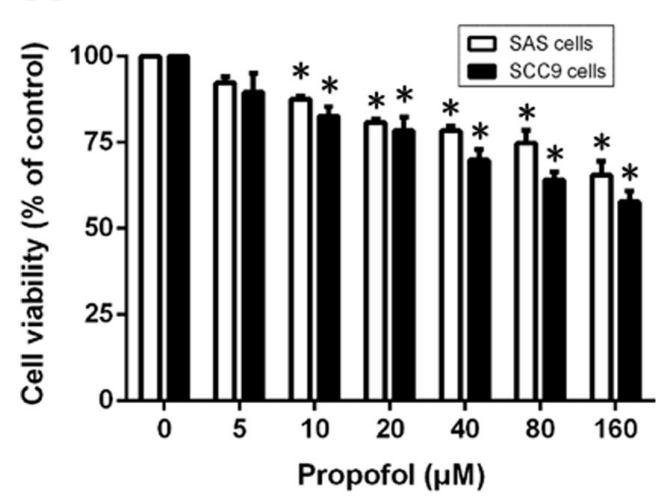

C

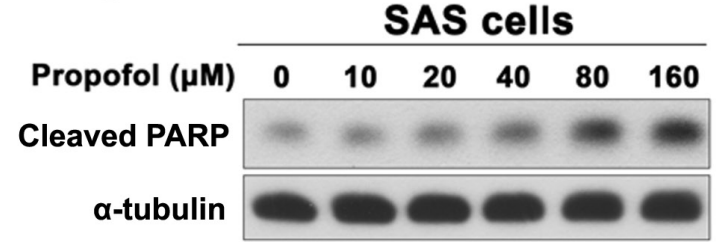

B

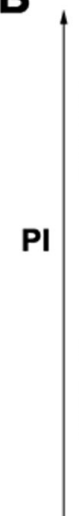

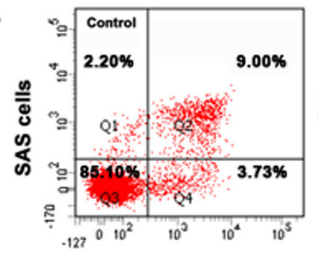
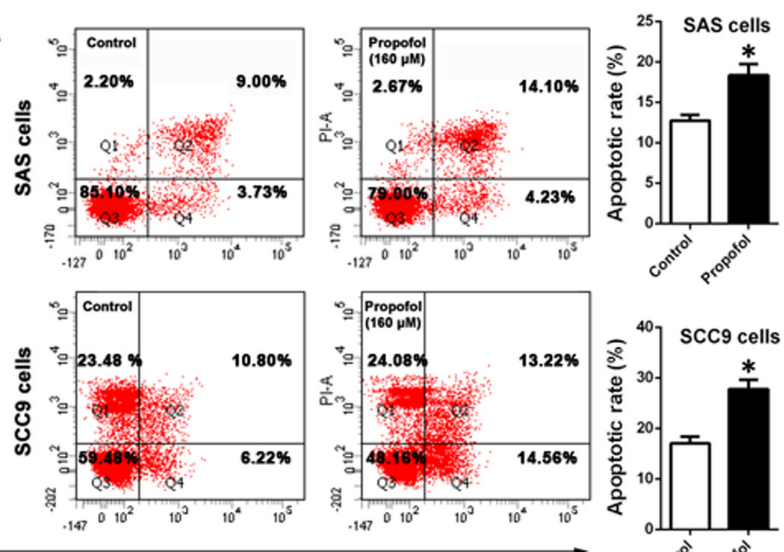

Annexin V-FITC

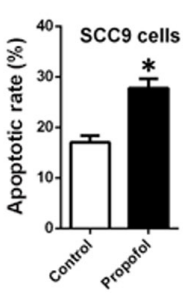

\section{SCC9 cells}

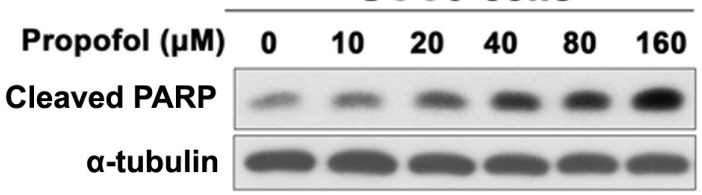

Figure 1. Propofol decreases oral squamous cell carcinoma cell viability and promotes cell apoptosis. (A) Effect of propofol on SAS ( $\mathrm{n}=4$ ) and SCC9 ( $=3$ ) cell viability. Cells were treated with $0-160 \mu \mathrm{M}$ propofol for $48 \mathrm{~h}$ and then cell viability assay was determined using MTT assays. (B) Cells were treated with $160 \mu \mathrm{M}$ propofol for $48 \mathrm{~h}$. Apoptosis was evaluated by Annexin V-FITC/PI staining and the ratio of apoptotic cells was quantified using flow cytometry. (SAS cells, $n=3$; SCC9 cells, $n=5)(C)$ Effect of propofol on cleaved PARP protein expression levels was determined by western blotting with $\alpha$-tubulin as the loading control $(\mathrm{n}=3)$. Cells were treated with increasing doses of propofol $(0-160 \mu \mathrm{M})$ for $48 \mathrm{~h}$. ${ }^{*} \mathrm{P}<0.05$ vs. control. PARP, poly(ADP-ribose) polymerase.

\section{Results}

Effect of propofol on anticancer activity in OSCC cells. To determine the cytotoxic effect of propofol on OSCC cells, SAS and SCC9 cells were incubated in media containing $0-160 \mu \mathrm{M}$ propofol for $48 \mathrm{~h}$, and then cell viability was determined using an MTT assay. As shown in Fig. 1A, propofol decreased OSCC cell viability in a dose-dependent manner; however, significance was only recorded at concentrations $>5 \mu \mathrm{M}$. To determine whether propofol induced OSCC cell apoptosis, Annexin V-FITC/PI staining-based flow cytometry was conducted to detect SAS and SCC9 cell apoptosis following treatment with propofol. Compared with the control groups $(12.73 \pm 0.7126$ and $17.02 \pm 1.337 \%$, respectively), propofol significantly increased the proportion of apoptotic cells in both SAS $(18.33 \pm 1.410 \%)$ and SCC9 $(27.78 \pm 1.827 \%)$ cells (Fig. 1B).

The expression levels of cleaved- poly(ADP-ribose) polymerase (PARP), a protein that is associated with apoptosis (25), were determined by western blotting to assess the effect of propofol on cell apoptosis. The results demonstrated that propofol treatment increased the expression of cleaved PARP increased in a concentration-dependent manner (Fig. 1C).

Propofol attenuates the secretion of multiple growth factors in OSCC cells. Numerous studies have demonstrated that growth factors secreted by tumor cells into the microenvironment are related to antiapoptosis effects $(19,26)$. To determine the effect of propofol on the secretion of growth factors, CM was used for an antibody array to detect changes in the secretion of growth factors by OSCC cells after treatment with propofol (Fig. 2A). The relative signal intensity for the growth factors was compared between untreated and propofol-treated SAS and SCC9 cells. SAS and SCC9 cells displayed similar results, with a total of 16 growth factors [AREG, basic fibroblast growth factor, beta-nerve growth factor, EGF, FGF-4, FGF-6, insulin like growth factor binding protein-4, insulin like growth factor-1, neurotrophin (NT)-3, NT-4, platelet derived growth factor receptor (PDGF R) $\alpha$, PDGF R $\beta$, TGF $\beta$, TGF $\beta 3$, VEGFR2 and VEGFR3] displaying a $>2$-fold reduction in secretion in the propofol-treated group compared with the untreated group (Fig. 2B).

Bioinformatics analysis of the clinical significance of the downregulation of secreted proteins in patients with HNSCC. To determine the clinical importance of these secreted proteins, GEPIA were used to determine differences in expression patterns between HNSCC tissues and healthy tissues. Compared with those in healthy tissues, the mRNA expression levels of AREG, PDGF R $\beta$, TGF- $\beta$ and TGF- $\beta 3$ were significantly upregulated in HNSCC tissues, whereas NT-3 was significantly downregulated (Fig. 3A).

GEPIA was also used to perform an OS analysis to determine the clinical relevance of these secreted proteins in terms of prognosis. The results demonstrated that high mRNA expression of AREG (log-rank $\mathrm{P}=0.00039$ ) and EGF (log-rank $\mathrm{P}=0.00087$ ) was significantly associated with a worse OS (Fig. 3B). However, high expression levels of PDGF R $\alpha$ (log-rank P=0.024), VEGFR2 (log-rank P=0.025) and VEGFR (log-rank $\mathrm{P}=0.036$ ) were significantly associated with an improved prognosis for patients with HNSCC. The 


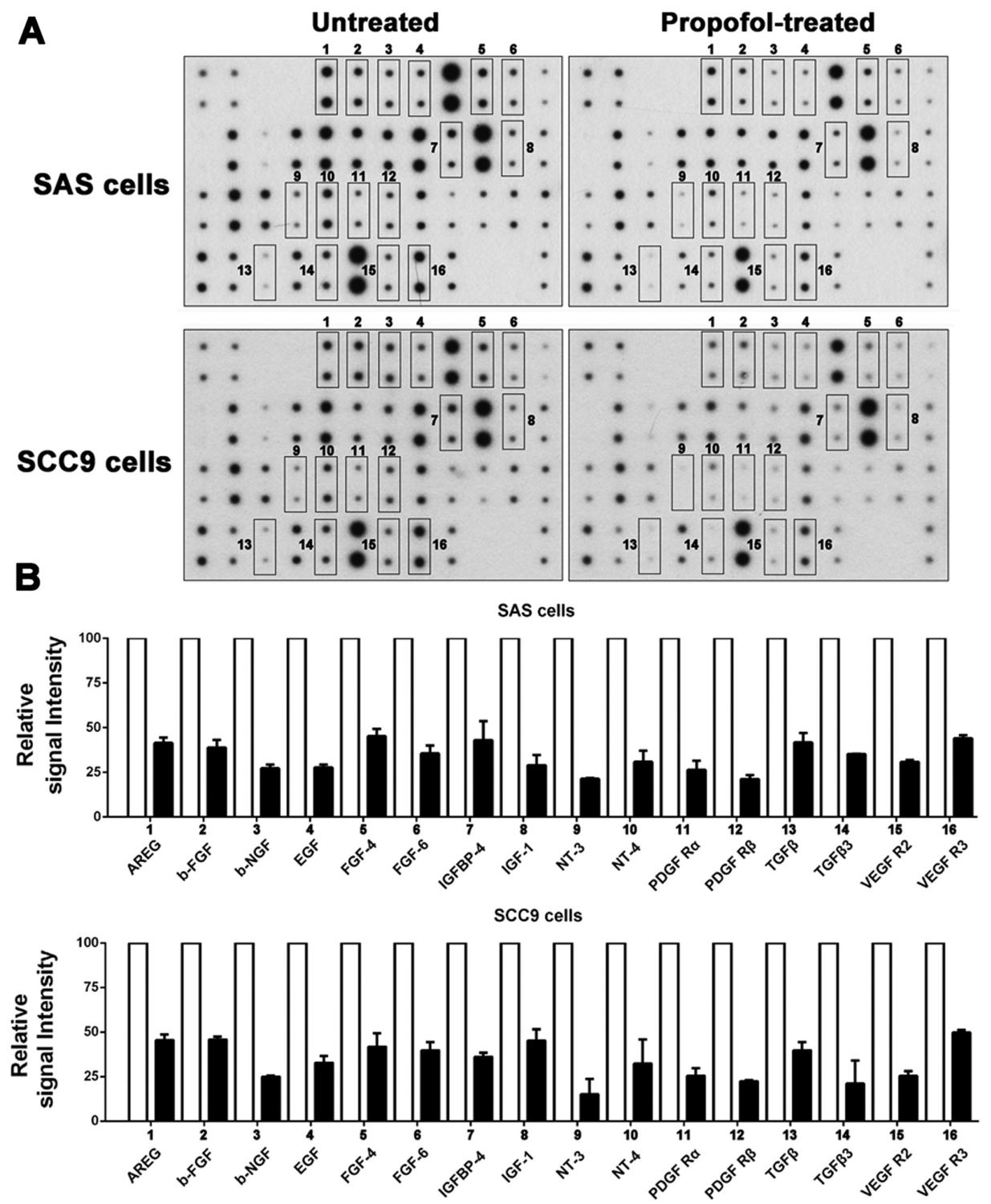

Figure 2. Effect of propofol on protein secretion in oral squamous cell carcinoma cells. (A) Cells were treated with $10 \mu \mathrm{M}$ propofol for $48 \mathrm{~h}$. Untreated cells were used as controls. Serum-free conditioned media was harvested and analyzed using a human growth factor antibody array. Each antibody was spotted in duplicate onto a membrane. The boxes with numbers indicate that the spots that were markedly reduced in size in the propofol-treated group compared with the untreated group (fold changes $>2$ ). (B) With reference to untreated cells, the intensity of the spots was quantified by densitometry analysis and displayed as a relative signal intensity. AREG, amphiregulin; b-FGF, basic fibroblast growth factor; b-NGF, beta-nerve growth factor; IGFBP, insulin like growth factor binding protein; IGF, insulin like growth factor; NT, neurotrophin; PDGF R, platelet derived growth factor receptor.

bioinformatics analysis results demonstrated that AREG was highly expressed in cancer tissues and associated with a poor prognosis, thus AREG was selected as the target gene for the present study.

Propofol reduces AREG expression in OSCC cells and may limit the activation of its related signaling pathways. The effect of propofol on AREG expression was investigated. SAS and SCC9 cells were treated with different concentrations of propofol $(0-160 \mu \mathrm{M})$. The results demonstrated that the mRNA expression level of AREG was significantly reduced at $160 \mu \mathrm{M}$ in SAS cells and significantly reduced at $20 \mu \mathrm{M}$ in SCC9 cells. (Fig. 4A). After propofol treatment, the effect of propofol on AREG protein expression was significantly reduced in a dose-dependent manner in both SAS and SCC9 cells. (Fig. 4B). The activation of specific kinases via extracellular stimulation of AREG may serve a crucial role in mediating cell functions. Therefore, OSCC cells were treated with AREG, and a human EGFR phosphorylation antibody array was used to determine the relative phosphorylation levels for 17 different EGF receptors.

In rAREG-treated SAS cells, there was more than twice the level of phosphorylation of EGFR (Tyr845) and ErbB2 (Tyr877) and 1.5 times the level of ErbB2 (Tyr1112) compared with that in untreated SAS cells (Fig. 4C). SCC9 cells displayed similar activation behavior, with an activation efficiency greater than that of SAS cells. As shown in Fig. 4C, the phosphorylation level of EGFR (Tyr1173) and ErbB4 (Tyr1284) increased $>1.5$ times and the phosphorylation level for EGFR (Tyr845), ErbB2 (Tyr877) and ErbB2 (Tyr1112) increased $>3$-fold.

AREG is the main ligand that is responsible for EGFR signal activation (27). AREG also induced Tyr845 


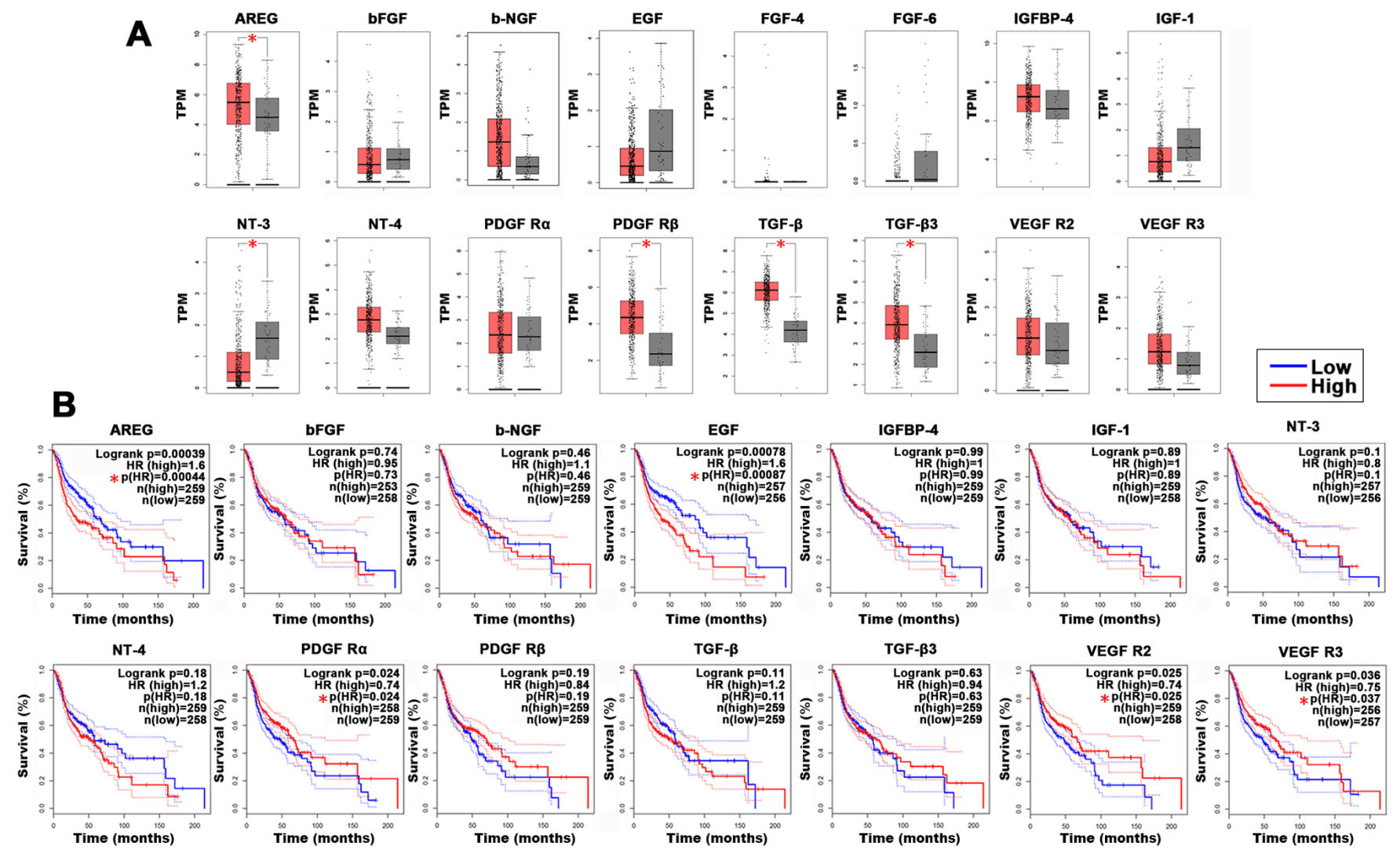

Figure 3. Association between decreased protein secretion and the clinical features of HNSCC. (A) Box plots indicating mRNA expression levels for candidate genes in HNSCC tissues (red) and normal tissue (gray) for The Cancer Genome Atlas datasets from GEPIA. The y-axes represent transformed log2 (TPM+1). The $\log 2 \mathrm{FCl}$ cutoff was 1 and the P-value cutoff was 0.05 . (B) Association between target genes and overall survival was determined using GEPIA. The solid line represents the survival curve and the dashed lines represents the $95 \%$ confidence interval. Log-rank $\mathrm{P}<0.05$ was considered to indicate a statistically significant difference. Patients with expression levels higher than the median are indicated by a red line and patients with expression levels lower than the median are indicated by a blue line. "P<0.05. HNSCC, head and neck squamous cell carcinoma; GEPIA, gene expression profile interactive analysis; TPM, transcripts per million; FC, fold change; HR, hazard ratio; b-FGF, basic fibroblast growth factor; b-NGF, beta-nerve growth factor; IGFBP, insulin like growth factor binding protein; IGF, insulin like growth factor; NT, neurotrophin; PDGF R, platelet derived growth factor receptor.

phosphorylation of EGFR in both SAS and SCC9 cells, so SAS and SCC9 cells were treated with increasing doses of rAREG $(50-100 \mathrm{ng} / \mathrm{ml})$ and the level of phosphorylated EGFR (Tyr845) was assessed via western blotting. AREG markedly induced EGFR (Tyr845) phosphorylation in SAS and SCC9 cells in a concentration-dependent manner (Fig. 4D).

To verify that propofol induced OSCC cell apoptosis by decreasing the expression of AREG, OSCC cells were pretreated with rAREG to assess whether this increased resistance to propofol. The results demonstrated that pretreatment with rAREG significantly increased the resistance of SAS and SCC9 cells to propofol (Fig. 4E). These results indicated that propofol suppressed the expression and secretion of AREG, which may limit AREG-induced EGFR activation and promote cell apoptosis.

Elevated AREG expression and its associated activation are related to the development of 5-FU resistance, but propofol alleviates resistance to 5-FU. To determine the relationship between AREG expression and 5-FU sensitivity in OSCC cells, different concentrations of 5-FU were used to establish cell lines with different degrees of 5-FU resistance. The results indicated that 5-FU resistance was gradually increased from SCC9, SCC9-FUR40, SCC9-FUR80 to SCC9-FUR160 cells, displaying significantly increased cell viability in SCC9-FUR160 cells compared with SCC9 cells (Fig. 5A).

The levels of AREG expression were elevated as 5-FU resistance increased (Fig. 5B). SCC9 and SCC9-FUR160 cells were then compared to determine whether highly resistant cells displayed a high level of AREG secretion and activation of the related signaling pathways. SCC9-FUR160 cells displayed higher protein expression levels of AREG compared with SCC9 cells (Fig. 5C). The relative expression of total EGFR and the phosphorylation of EGFR (Tyr845) was also notably higher in SCC9-FUR160 cells compared with that in SCC9 cells (Fig. 5D).

To verify that AREG mediated 5-FU resistance, AREG overexpression vector or empty vector was used to transiently transfect SCC9 cells and then the sensitivity to 5-FU was assessed. AREG overexpression was confirmed by western blotting (Fig. 5E). The results demonstrated that AREG overexpression significantly increased resistance to $5-\mathrm{FU}$ for SCC9-FUR160 cells (Fig. 5F).

To determine whether propofol increased sensitivity to 5-FU for OSCC cells, SCC9 and SCC9-FUR160 cells were pretreated with propofol for $24 \mathrm{~h}$ and then combined with 5-FU for another $48 \mathrm{~h}$. As the antibody array analysis results showed that treatment of cells with $10 \mu \mathrm{M}$ propofol markedly reduced the secretion of a number of growth factors, cells were treated 

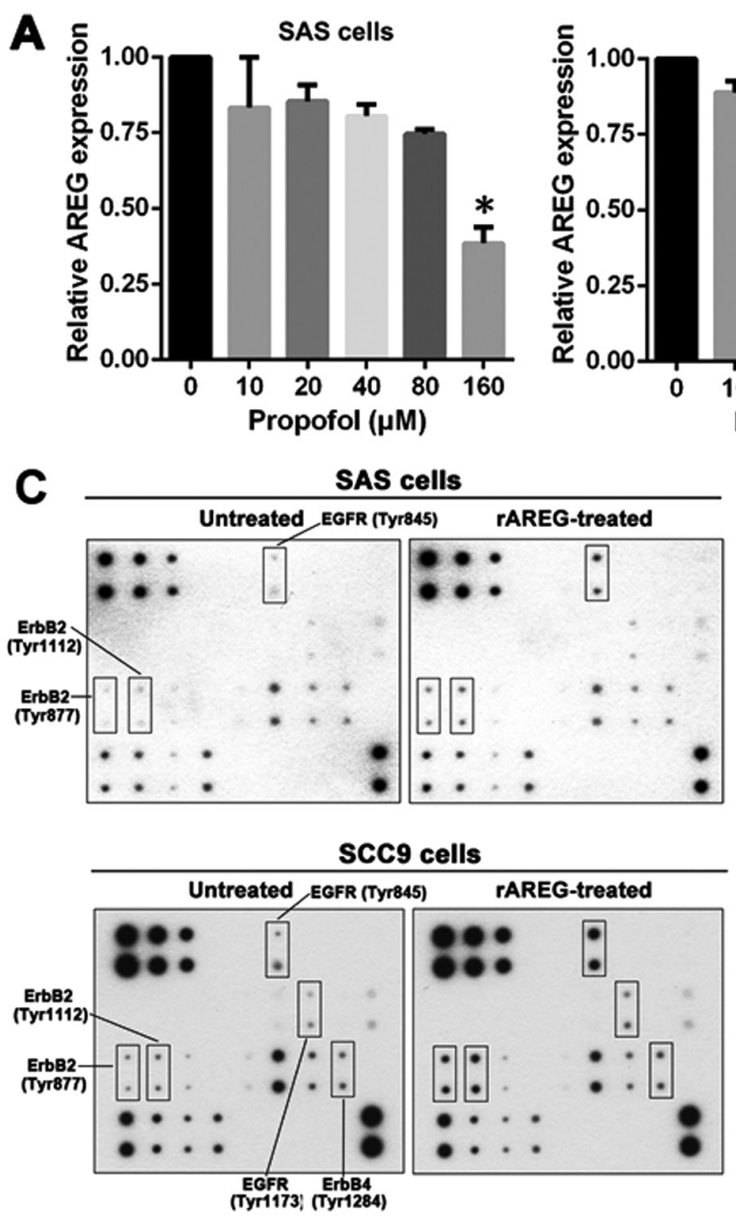

D
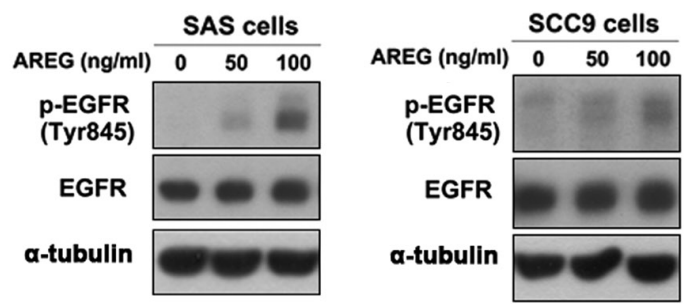

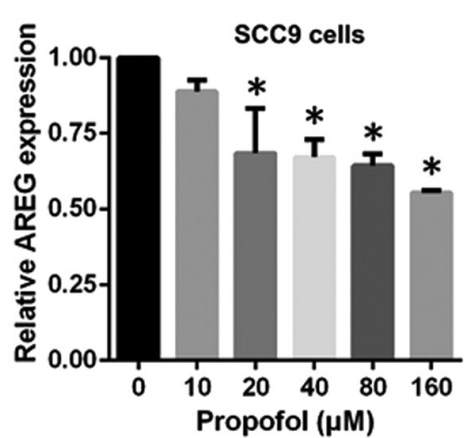

B
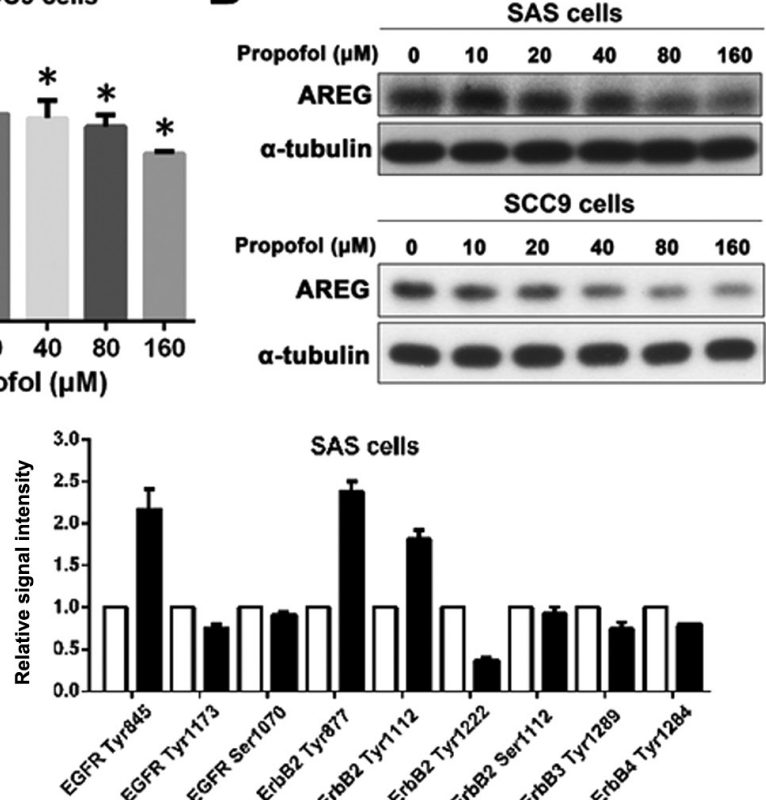

SAS cells

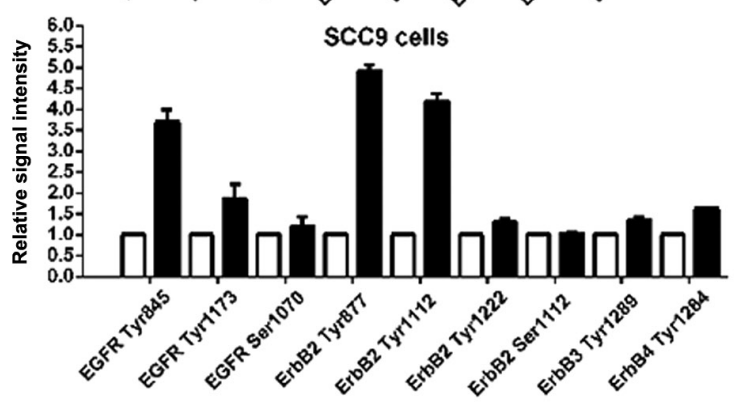

E

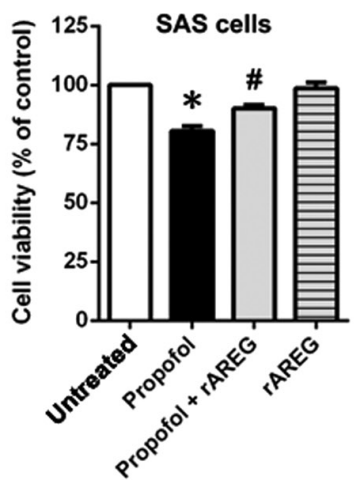

Figure 4. Propofol inhibits AREG expression in oral squamous cell carcinoma cells, which may reduce the activation of its related signaling pathways and lead to cell apoptosis. (A) mRNA and (B) protein expression levels of AREG were determined by reverse transcription-quantitative PCR (n=4-6) and western blotting ( $\mathrm{n}=3)$, respectively. SAS and SCC9 cells were treated with propofol $(10-160 \mu \mathrm{M})$ for $48 \mathrm{~h}$. ${ }^{*} \mathrm{P}<0.05$ vs. untreated control. (C) SAS and SCC9 cells were stimulated with or without rAREG $(50 \mathrm{ng} / \mathrm{ml})$ for $15 \mathrm{~min}$. The activation of EGFR was determined using a human EGFR phosphorylation antibody array. (D) SAS and SCC9 cells were stimulated with different concentrations of rAREG (50-100 ng/ml) for 15 min and then the cell lysates were analyzed by western blotting using anti-p-EGFR (Tyr845) or anti-EGFR antibodies ( $\mathrm{n}=3$ ). (E) SAS cells were pretreated with $\mathrm{rAREG}(50 \mathrm{ng} / \mathrm{ml})$ for $4 \mathrm{~h}$ and then stimulated with $40 \mu \mathrm{M}$ propofol for $48 \mathrm{~h}(\mathrm{n}=4)$. SCC9 cells were pretreated with rAREG $(100 \mathrm{ng} / \mathrm{ml})$ for $4 \mathrm{~h}$ and then stimulated with $80 \mu \mathrm{M}$ propofol for $48 \mathrm{~h}$ ( $\mathrm{n}=4)$. Cell viability was determined using an MTT assay $(n=4)$. Data are presented as the mean $\pm \mathrm{SEM}$. ${ }^{*} \mathrm{P}<0.05$ vs. Untreated control group; ${ }^{\mathrm{P}}<0.05$ vs. propofol. AREG, amphiregulin; rAREG, recombinant AREG; p, phosphorylated.

with $10 \mu \mathrm{M}$ propofol. Propofol slightly increased 5-FU cytotoxicity in SCC9 cells, but significantly increased sensitivity to 5-FU in SCC9-FUR160 cells compared with 5-FU alone (Fig. 5G). These results demonstrated that propofol alleviated resistance to 5-FU, potentially by decreasing the expression and secretion of AREG.

\section{Discussion}

Propofol is one of the most commonly used intravenous anesthetics in clinical practice (28). The present study aimed to determine the effect of propofol on the biological behavior and secretion of growth factors in OSCC cells. The results 


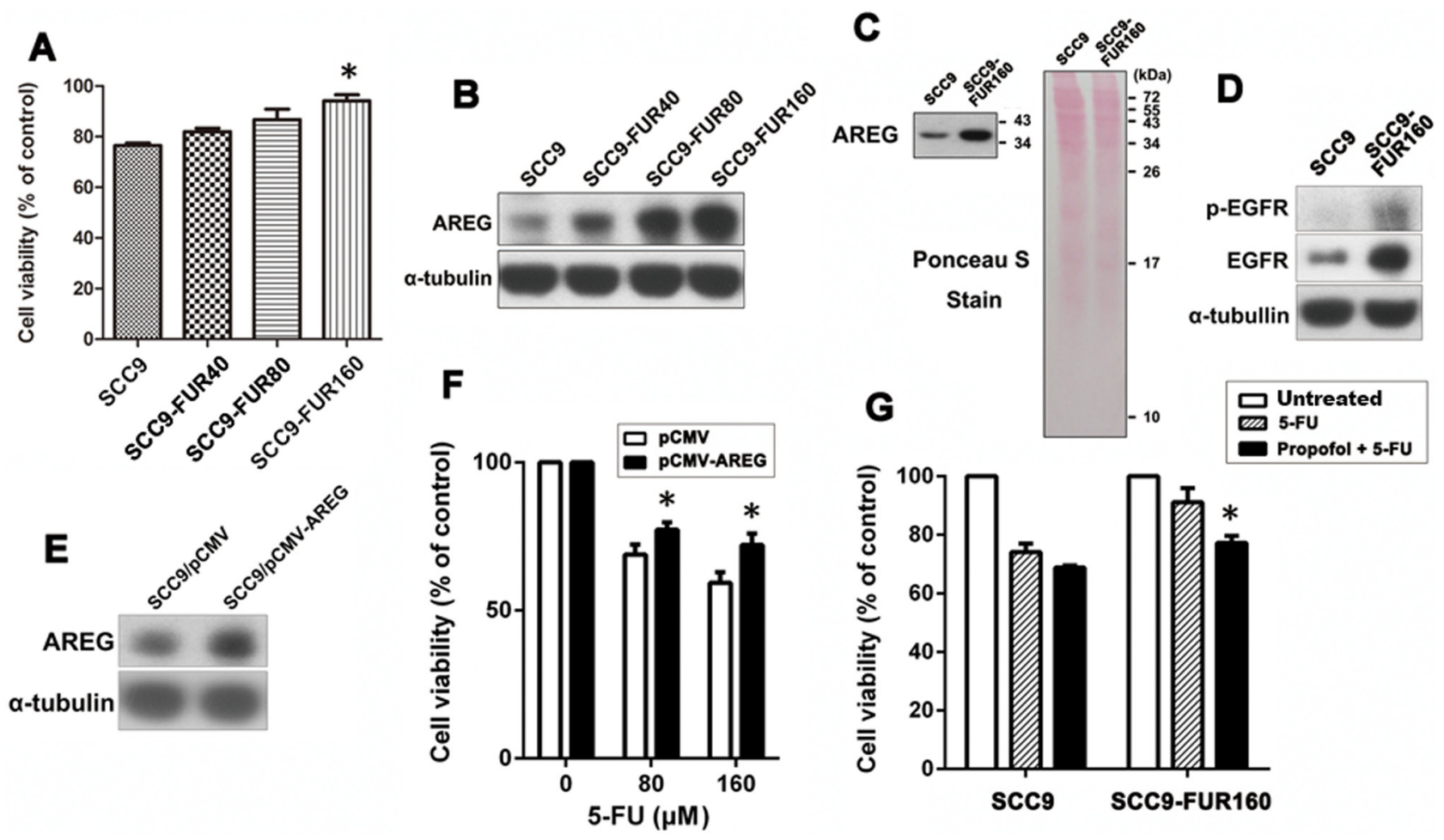

Figure 5. AREG upregulation is related to the development of 5-FU resistance, but propofol alleviates 5-FU resistance. (A) Cells were treated with $160 \mu \mathrm{M}$ 5 -FU for $48 \mathrm{~h}$ and then cell viability was determined by performing MTT assays. Data are presented as the mean \pm SEM $(\mathrm{n}=3)$. ${ }^{*} \mathrm{P}<0.05 \mathrm{vs}$. SCC9. (B) AREG protein expression levels in 5-FU-resistant cell sub-lines and their parental cells were analyzed by western blotting with $\alpha$-tubulin as the loading control ( $\mathrm{n}=3$ ). (C) Secreted levels of AREG in the cell culture media of SCC9 and SCC9-FUR160 cells were analyzed using western blotting (n=3). Ponceau S staining demonstrated that equivalent amounts of total protein were loaded on each lane. (D) Basal expression of p-EGFR and total EGFR in SCC9 and SCC9-FUR160 cells was evaluated by western blotting $(\mathrm{n}=3)$. (E) SCC9 cells were transiently transfected with $\mathrm{pCMV3-AREG}$ and then the protein expression level of AREG was analyzed by western blotting $(\mathrm{n}=3)$. (F) Cells were treated with increasing concentrations of propofol $(0-160 \mu \mathrm{M})$ for $72 \mathrm{~h}$. Effect of AREG overexpression on 5-FU-induced cytotoxicity was determined by performing MTT assays $(\mathrm{n}=4)$. " $\mathrm{P}<0.05 \mathrm{vs}$. pCMV. (G) Cells were treated with propofol $(10 \mu \mathrm{M})$ for $24 \mathrm{~h}$ and then stimulated with 5 -FU $(40 \mu \mathrm{M})$ in the presence of $10 \mu \mathrm{M}$ propofol for $48 \mathrm{~h}$. Cell viability was then assessed by performing MTT assays (n=3). ${ }^{*} \mathrm{P}<0.05 \mathrm{vs}$. 5-FU treatment alone. AREG, amphiregulin; 5-FU, 5-fluorouracil; p, phosphorylated; FUR, 5-FU-resistant. F, 5-FU.

demonstrated that propofol was cytotoxic to OSCC cells and downregulated the secretion of several growth factors. The GEPIA database results indicated that AREG was highly expressed in cancer tissues and associated with poor prognosis for patients with OSCC, thus AREG was selected for further investigation. AREG is the ligand of EGFR (27). The results of the current study revealed that propofol downregulated the secretion of AREG, which may have reduced the activation of the EGFR pathway. To the best of our knowledge, the present study was the first to demonstrate that propofol regulated AREG to exert an antitumor effect.

AREG is one of the ligands of EGFR that is shed from the membrane through the proteolytic process of disintegrin and metalloprotease 17 (ADAM17) and is converted into an active soluble form, which activates receptors (29). Previous studies have reported that AREG upregulation is related to drug resistance and a failure of treatment for multiple types of cancer, including OSCC (30-32). EGFR in HNSCC is also $15 \%$ upregulated, and high EGFR expression is associated with a low survival rate (33). Similarly, $>80 \%$ of OSCC cases exhibit EGFR upregulation, which is highly correlated with carcinogenic, antiapoptotic and aggressive phenotypes (34-36).

Increasing evidence shows that anesthetics can affect tumor progression (37) and long-term outcomes for patients (38), especially in terms of cancer recurrence (39). It has been reported that different anesthetics can have opposite effects on cancer development (40). Therefore, the identification of an appropriate anesthetic to provide adequate anesthesia management for patients with cancer is important.

Previous studies show that propofol can have an anticancer effect in different human cancer cells, including osteosarcoma (41), hepatocellular carcinoma (42), lung cancer (43), ovarian cancer (44), cervical cancer (45), glioma (46), gastric cancer (47), breast cancer (48) and colorectal cancer cells (49). A previous study showed that propofol displayed an anticancer effect on OSCC cells by inhibiting cell proliferation and promoting cell apoptosis (50). Retrospective analyses demonstrated that propofol-based total intravenous anesthesia significantly reduces postoperative mortality for patients with cancer, so propofol may be involved in tumor suppression $(51,52)$.

Tumors are heterogeneous tissues that are surrounded by the tumor microenvironment. The complex microenvironment for a tumor is composed of cancer cells, stromal cells, immune cells and extracellular matrix. The tumor microenvironment is related to tumor progression and affects tumor growth, metastasis, drug resistance and recurrence (53). The regulation of the microenvironment for tumors has also become a new strategy for cancer treatment (54). 
At present, it is known that propofol displays anti-inflammatory properties (55). The present study demonstrated that propofol decreased the secretion of a variety of growth factors, which implied that the anti-inflammatory effect of propofol may be achieved via the secretion of inflammatory factors. However, the antibody array used in the present study only analyzed the secretion of 41 growth factors in OSCC cells. To further assess the anti-inflammatory effects of propofol, future studies should select a suitable immune cell line for further analysis.

Previous studies have reported that propofol inhibits the proliferation, metastasis and progress of pancreatic cancer by inhibiting the expression of ADAM $(56,57)$. The ADAM family is involved in the process of proteolytic shedding of membrane-associated proteins, which causes cleavage of transmembrane proteins and solubilizes the complete ectodomain of cytokines, growth factors, receptors and adhesion molecules, which changes in the tumor microenvironment (58).

A previous study also showed that propofol inhibits the release of VEGF-C, which is induced by breast surgery (59). VEGF-C has been shown to be involved in lymphangiogenesis to promote cancer metastasis. VEGF-C has also been observed to increase cell proliferation and migration, contributing to OSCC progression (60). Extracellular vesicles (EVs) are also important facilitators of malignant cell communication. Propofol has been shown to exhibit anticancer activity by inhibiting the release of EVs during a cancer resection, which is related to tumor progression and prognosis $(61,62)$.

Numerous studies have shown that propofol may be involved in tumor suppression, displaying an important effect on the process of tumor spread and chemotherapy $(8,9,28,63,64)$; however, the underlying molecular mechanisms are not completely understood. The present study investigated the effect of propofol on the secretion profile of growth factors by OSCC cells. To determine the clinical significance of the altered proteins, the GEPIA database was used and the results indicated that AREG was significantly elevated in cancer tissues and associated with a poor prognosis for patients with OSCC. The present study also determined that AREG expression and the activation of its related signaling pathways was involved in 5-FU-resistance in OSCC. Pretreatment with propofol increased 5-FU sensitivity in 5-FU resistant cells. Therefore, the results of the present study provided a theoretical basis for the combined use of propofol and 5-FU for the treatment of OSCC.

\section{Acknowledgements}

Not applicable.

\section{Funding}

The present study was supported by the Ditmanson Medical Foundation of Chia-Yi Christian Hospital (grant no. R109-16).

\section{Availability of data and materials}

The datasets used and/or analyzed during the current study are available from the corresponding author on reasonable request.

\section{Authors' contributions}

JCC and MSC conceived and designed the current study. KSY and PCC performed data analysis and wrote the manuscript. YPW performed the experiments. MJH and INL were responsible for data interpretation and manuscript revision. JCC revised the manuscript critically for important intellectual content. All authors have read and approved the final manuscript. JCC and MSC confirmed the authenticity of all the raw data.

\section{Ethics approval and consent to participate}

Not applicable.

\section{Patient consent for publication}

Not applicable.

\section{Competing interests}

The authors declare that they have no competing interests.

\section{References}

1. Curado MP and Hashibe M: Recent changes in the epidemiology of head and neck cancer. Curr Opin Oncol 21: 194-200, 2009.

2. Scully C and Bagan J: Oral squamous cell carcinoma overview. Oral Oncol 45: 301-308, 2009.

3. Chi AC, Day TA and Neville BW: Oral cavity and oropharyngeal squamous cell carcinoma - an update. CA Cancer J Clin 65: 401-421, 2015.

4. Longley DB, Harkin DP and Johnston PG: 5-fluorouracil: Mechanisms of action and clinical strategies. Nat Rev Cancer 3: 330-338, 2003.

5. Nagata M, Nakayama H, Tanaka T, Yoshida R, Yoshitake Y, Fukuma D, Kawahara K, Nakagawa Y, Ota K, Hiraki A, et al: Overexpression of cIAP2 contributes to 5-FU resistance and a poor prognosis in oral squamous cell carcinoma. Br J Cancer 105: 1322-1330, 2011.

6. Sahinovic MM, Struys MMRF and Absalom AR: Clinical Pharmacokinetics and Pharmacodynamics of Propofol. Clin Pharmacokinet 57: 1539-1558, 2018.

7. Vasileiou I, Xanthos T, Koudouna E, Perrea D, Klonaris C, Katsargyris A and Papadimitriou L: Propofol: A review of its non-anaesthetic effects. Eur J Pharmacol 605: 1-8, 2009.

8. Song J, Shen Y, Zhang J and Lian Q: Mini profile of potential anticancer properties of propofol. PLoS One 9: e114440, 2014.

9. Gong T, Ning X, Deng Z, Liu M, Zhou B, Chen X, Huang S, Xu Y, Chen Z and Luo R: Propofol-induced miR-219-5p inhibits growth and invasion of hepatocellular carcinoma through suppression of GPC3-mediated Wnt/ $\beta$-catenin signalling activation. J Cell Biochem 120: 16934-16945, 2019.

10. Ye LL, Cheng ZG, Cheng XE and Huang YL: Propofol regulates miR-1-3p/IGF1 axis to inhibit the proliferation and accelerates apoptosis of colorectal cancer cells. Toxicol Res (Camb) 10: 696-705, 2021.

11. Jun IJ, Jo JY, Kim JI, Chin JH, Kim WJ, Kim HR, Lee EH and Choi IC: Impact of anesthetic agents on overall and recurrence-free survival in patients undergoing esophageal cancer surgery: A retrospective observational study. Sci Rep 7: 14020,2017

12. Zheng X, Wang Y, Dong L, Zhao S, Wang L, Chen H, Xu Y and Wang G: Effects of propofol-based total intravenous anesthesia on gastric cancer: A retrospective study. OncoTargets Ther 11: 1141-1148, 2018.

13. Wu ZF, Lee MS, Wong CS, Lu CH, Huang YS, Lin KT, Lou YS, Lin C, Chang YC and Lai HC: Propofol-based Total Intravenous Anesthesia Is Associated with Better Survival Than Desflurane Anesthesia in Colon Cancer Surgery. Anesthesiology 129: 932-941, 2018. 
14. Lai HC, Lee MS, Lin C, Lin KT, Huang YH, Wong CS, Chan SM and Wu ZF: Propofol-based total intravenous anaesthesia is associated with better survival than desflurane anaesthesia in hepatectomy for hepatocellular carcinoma: A retrospective cohort study. Br J Anaesth 123: 151-160, 2019.

15. Lai HC, Lee MS, Lin KT, Chan SM, Chen JY, Lin YT and Wu ZF: Propofol-based total intravenous anesthesia is associated with better survival than desflurane anesthesia in intrahepatic cholangiocarcinoma surgery. Medicine (Baltimore) 98: e18472, 2019.

16. Guerrero Orriach JL, Raigon Ponferrada A, Malo Manso A, Herrera Imbroda B, Escalona Belmonte JJ, Ramirez Aliaga M, Ramirez Fernandez A, Diaz Crespo J, Soriano Perez AM, Fontaneda Heredia A, et al: Anesthesia in Combination with Propofol Increases Disease-Free Survival in Bladder Cancer Patients Who Undergo Radical Tumor Cystectomy as Compared to Inhalational Anesthetics and Opiate-Based Analgesia. Oncology 98: 161-167, 2020.

17. Nazemi $M$ and Rainero E: Cross-Talk Between the Tumor Microenvironment, Extracellular Matrix, and Cell Metabolism in Cancer. Front Oncol 10: 239, 2020.

18. Wilson TR, Fridlyand J, Yan Y, Penuel E, Burton L, Chan E, Peng J, Lin E, Wang Y, Sosman J, et al: Widespread potential for growth-factor-driven resistance to anticancer kinase inhibitors. Nature 487: 505-509, 2012

19. Nisar S, Yousuf P, Masoodi T, Wani NA, Hashem S, Singh M, Sageena G, Mishra D, Kumar R, Haris M, et al: Chemokine-Cytokine Networks in the Head and Neck Tumor Microenvironment. Int J Mol Sci 22: 4584, 2021.

20. Mughees M, Sengupta A, Khowal S and Wajid S: Mechanism of tumour microenvironment in the progression and development of oral cancer. Mol Biol Rep 48: 1773-1786, 2021.

21. Sen $\mathrm{Y}$, Xiyang $\mathrm{H}$ and $\mathrm{Yu} \mathrm{H}$ : Effect of thoracic paraspinal block-propofol intravenous general anesthesia on VEGF and TGF- $\beta$ in patients receiving radical resection of lung cancer. Medicine (Baltimore) 98: e18088, 2019.

22. Chen Z, Dodig-Crnković T, Schwenk JM and Tao SC: Current applications of antibody microarrays. Clin Proteomics 15: 7 , 2018.

23. Tang Z, Li C, Kang B, Gao G, Li C and Zhang Z: GEPIA: A web server for cancer and normal gene expression profiling and interactive analyses. Nucleic Acids Res 45W: W98-W102, 2017.

24. Livak KJ and Schmittgen TD: Analysis of relative gene expression data using real-time quantitative PCR and the 2(-Delta Delta C(T)) Method. Methods 25: 402-408, 2001

25. Boulares AH, Yakovlev AG, Ivanova V, Stoica BA, Wang G, Iyer S and Smulson M: Role of poly(ADP-ribose) polymerase (PARP) cleavage in apoptosis. Caspase 3-resistant PARP mutant increases rates of apoptosis in transfected cells. J Biol Chem 274 22932-22940, 1999.

26. Castells M, Thibault B, Delord JP and Couderc B: Implication of tumor microenvironment in chemoresistance: Tumor-associated stromal cells protect tumor cells from cell death. Int J Mol Sci 13 9545-9571, 2012

27. Berasain C and Avila MA: Amphiregulin. Semin Cell Dev Biol 28: 31-41, 2014.

28. Bateman BT and Kesselheim AS: Propofol as a transformative drug in anesthesia: Insights from key early investigators. Drug Discov Today 20: 1012-1017, 2015

29. Busser B, Sancey L, Brambilla E, Coll JL and Hurbin A: The multiple roles of amphiregulin in human cancer. Biochim Biophys Acta 1816: 119-131, 2011.

30. Gao J, Ulekleiv $\mathrm{CH}$ and Halstensen TS: Epidermal growth factor (EGF) receptor-ligand based molecular staging predicts prognosis in head and neck squamous cell carcinoma partly due to deregulated EGF- induced amphiregulin expression. J Exp Clin Cancer Res 35: 151, 2016.

31. Hsieh MJ, Chen YH, Lee IN, Huang C, Ku YJ and Chen JC: Secreted amphiregulin promotes vincristine resistance in ora squamous cell carcinoma. Int J Oncol 55: 949-959, 2019.

32. Bourova-Flin E, Derakhshan S, Goudarzi A, Wang T, Vitte AL, Chuffart F, Khochbin S, Rousseaux S and Aminishakib P: The combined detection of Amphiregulin, Cyclin A1 and DDX20/Gemin3 expression predicts aggressive forms of oral squamous cell carcinoma. Br J Cancer 125: 1122-1134, 2021.

33. Bossi P, Resteghini C, Paielli N, Licitra L, Pilotti S and Perrone F: Prognostic and predictive value of EGFR in head and neck squamous cell carcinoma. Oncotarget 7: 74362-74379, 2016.
34. Sarkis SA, Abdullah BH, Abdul Majeed BA and Talabani NG: Immunohistochemical expression of epidermal growth factor receptor (EGFR) in oral squamous cell carcinoma in relation to proliferation, apoptosis, angiogenesis and lymphangiogenesis. Head Neck Oncol 2: 13, 2010.

35. Son HK, Kim D, Lim Y, Kim J and Park I: A novel TGF- $\beta$ receptor II mutation (I227T/N236D) promotes aggressive phenotype of oral squamous cell carcinoma via enhanced EGFR signaling. BMC Cancer 20: 1163, 2020.

36. Tsou HH, Tsai HC, Chu CT, Cheng HW, Liu CJ, Lee CH, Liu TY and Wang HT: Cigarette Smoke Containing Acrolein Upregulates EGFR Signaling Contributing to Oral Tumorigenesis In Vitro and In Vivo. Cancers (Basel) 13: 3544, 2021.

37. Yang W, Cai J, Zabkiewicz C, Zhang H, Ruge F and Jiang WG: The Effects of Anesthetics on Recurrence and Metastasis of Cancer, and Clinical Implications. World J Oncol 8: 63-70, 2017.

38. Cassinello F, Prieto I, del Olmo M, Rivas S and Strichartz GR: Cancer surgery: How may anesthesia influence outcome? J Clin Anesth 27: 262-272, 2015.

39. Snyder GL and Greenberg S: Effect of anaesthetic technique and other perioperative factors on cancer recurrence. Br J Anaesth 105: 106-115, 2010.

40. Plein LM and Rittner HL: Opioids and the immune system friend or foe. Br J Pharmacol 175: 2717-2725, 2018

41. Ye Z, Jingzhong L, Yangbo L, Lei C and Jiandong Y: Propofol inhibits proliferation and invasion of osteosarcoma cells by regulation of microRNA-143 expression. Oncol Res 21: 201-207, 2013.

42. Zhang J, Wu GQ, Zhang Y, Feng ZY and Zhu SM: Propofol induces apoptosis of hepatocellular carcinoma cells by upregulation of microRNA-199a expression. Cell Biol Int 37: 227-232, 2013.

43. Cui WY, Liu Y, Zhu YQ, Song T and Wang QS: Propofol induces endoplasmic reticulum (ER) stress and apoptosis in lung cancer cell H460. Tumour Biol 35: 5213-5217, 2014.

44. Su Z, Hou XK and Wen QP: Propofol induces apoptosis of epithelial ovarian cancer cells by upregulation of microRNA let-7i expression. Eur J Gynaecol Oncol 35: 688-691, 2014.

45. Zhang D, Zhou XH, Zhang J, Zhou YX, Ying J, Wu GQ and Qian JH: Propofol promotes cell apoptosis via inhibiting HOTAIR mediated mTOR pathway in cervical cancer. Biochem Biophys Res Commun 468: 561-567, 2015.

46. Xu J, Xu W and Zhu J: Propofol suppresses proliferation and invasion of glioma cells by upregulating microRNA-218 expression. Mol Med Rep 12: 4815-4820, 2015.

47. Peng Z and Zhang Y: Propofol inhibits proliferation and accelerates apoptosis of human gastric cancer cells by regulation of microRNA-451 and MMP-2 expression. Genet Mol Res 15: gmr7078, 2016

48. Yu B, Gao W, Zhou H, Miao X, Chang Y, Wang L, Xu M and Ni G: Propofol induces apoptosis of breast cancer cells by downregulation of miR-24 signal pathway. Cancer Biomark 21: 513-519, 2018.

49. Li Y, Dong W, Yang H and Xiao G: Propofol suppresses proliferation and metastasis of colorectal cancer cells by regulating miR-124-3p.1/AKT3. Biotechnol Lett 42: 493-504, 2020.

50. Gao C, Ren C, Liu Z, Zhang L, Tang R and Li X: GAS5, a FoxO1-actived long noncoding RNA, promotes propofol-induced oral squamous cell carcinoma apoptosis by regulating the miR-1297-GSK3 $\beta$ axis. Artif Cells Nanomed Biotechnol 47: 3985-3993, 2019

51. Wigmore TJ, Mohammed K and Jhanji S: Long-term Survival for Patients Undergoing Volatile versus IV Anesthesia for Cancer Surgery: A Retrospective Analysis. Anesthesiology 124: 69-79, 2016.

52. Lai HC, Lee MS, Lin KT, Huang YH, Chen JY, Lin YT, Hung KC and Wu ZF: Propofol-based total intravenous anesthesia is associated with better survival than desflurane anesthesia in robot-assisted radical prostatectomy. PLoS One 15: e0230290, 2020.

53. Wu $\mathrm{T}$ and Dai Y: Tumor microenvironment and therapeutic response. Cancer Lett 387: 61-68, 2017.

54. Zhang Y, Ho SH, Li B, Nie G and Li S: Modulating the tumor microenvironment with new therapeutic nanoparticles: A promising paradigm for tumor treatment. Med Res Rev 40: 1084-1102, 2020

55. Chen RM, Chen TG, Chen TL, Lin LL, Chang CC, Chang HC and $\mathrm{Wu} \mathrm{CH}$ : Anti-inflammatory and antioxidative effects of propofol on lipopolysaccharide-activated macrophages. Ann N Y Acad Sci 1042: 262-271, 2005. 
56. Gao Y, Yu X, Zhang F and Dai J: Propofol inhibits pancreatic cancer progress under hypoxia via ADAM8. J Hepatobiliary Pancreat Sci 26: 219-226, 2019.

57. Yu X, Shi J, Wang X and Zhang F: Propofol affects the growth and metastasis of pancreatic cancer via ADAM8. Pharmacol Rep 72: 418-426, 2020

58. Murphy G: The ADAMs: Signalling scissors in the tumour microenvironment. Nat Rev Cancer 8: 929-941, 2008.

59. Yan T, Zhang GH, Wang BN, Sun L and Zheng H: Effects of propofol/remifentanil-based total intravenous anesthesia versus sevoflurane-based inhalational anesthesia on the release of VEGF-C and TGF- $\beta$ and prognosis after breast cancer surgery: A prospective, randomized and controlled study. BMC Anesthesiol 18: 131, 2018.

60. Shigetomi S, Imanishi Y, Shibata K, Sakai N, Sakamoto K, Fujii R, Habu N, Otsuka K, Sato Y, Watanabe Y, et al: VEGF-C/Flt-4 axis in tumor cells contributes to the progression of oral squamous cell carcinoma via upregulating VEGF-C itself and contactin-1 in an autocrine manner. Am J Cancer Res 8: 2046-2063, 2018.
61. Zhang J, Shan WF, Jin TT, Wu GQ, Xiong XX, Jin HY and Zhu SM: Propofol exerts anti-hepatocellular carcinoma by microvesicle-mediated transfer of miR-142-3p from macrophage to cancer cells. J Transl Med 12: 279, 2014.

62. Buschmann D, Brandes F, Lindemann A, Maerte M, Ganschow P, Chouker A, Schelling G, Pfaffl MW and Reithmair M: Propofol and Sevoflurane Differentially Impact MicroRNAs in Circulating Extracellular Vesicles during Colorectal Cancer Resection: A Pilot Study. Anesthesiology 132: 107-120, 2020.

63. Wang J, Cheng CS, Lu Y, Ding X, Zhu M, Miao C and Chen J: Novel Findings of Anti-cancer Property of Propofol. Anticancer Agents Med Chem 18: 156-165, 2018.

64. Cramer JD, Burtness B, Le QT and Ferris RL: The changing therapeutic landscape of head and neck cancer. Nat Rev Clin Oncol 16: 669-683, 2019.

(i) $\odot$ This work is licensed under a Creative Commons Attribution-NonCommercial-NoDerivatives 4.0 International (CC BY-NC-ND 4.0) License. 